\title{
Households and families: Implications of changing census definitions for analyses using the ONS Longitudinal Study
}

Emily Grundy, Rachel Stuchbury and Harriet Young

Centre for Longitudinal Study Information and User Support (CeLSIUS), London School of Hygiene \& Tropical Medicine

\section{Abstract}

The ONS Longitudinal Study (LS) includes information from the 1971, 1981, 1991 and 2011 censuses. This article explains definitional differences over time, and their implications for household and family classifications. 


\section{Contents}

Abstract 64

Introduction

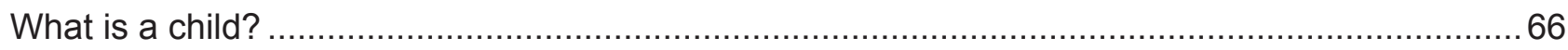

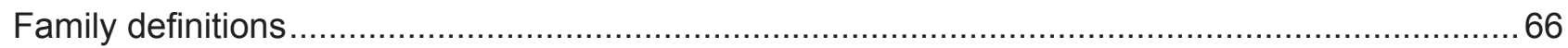

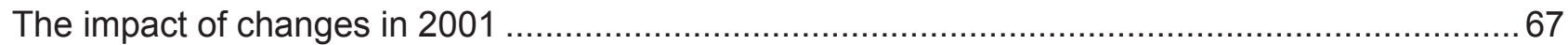

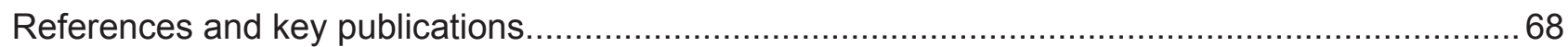

\section{List of tables}

Table 1 Distribution of ONS Longitudinal Study members by family/household type in 2001 using the 2001 and 1991 (and earlier) definitions of a child.... 


\section{Introduction}

The strengths of the ONS Longitudinal Study (LS) of England and Wales include the fact that information on all co-residents of LS sample members is available at each census point, together with information on family and household type (more information on family and household definitions and classifications is available in the CeLSIUS training module on households and families) ${ }^{1}$. The LS is thus a valuable resource for those interested in, for example, changes over the life course in the types of household people live in and those who want to compare distributions of household and family types at different time points in order to investigate period changes. For researchers interested in either approach, consistency of definitions is important. The ONS LS now includes information from the 1971, 1981, 1991 and 2001 Censuses. Changes in definitions between the first three of these censuses were relatively minor ${ }^{2}$, but in 2001 there was a more substantial change arising from a revised definition of a child. In this paper we explain this difference, its implications for household and family classifications, and offer a link to code (in STATA) which can be used by those wanting consistent definitions over time.

\section{What is a child?}

In the 2001 UK Census a child was defined as an individual of any age or marital status, not themselves part of a co-residing couple or a parent, grand-parent or step-parent of anyone else in the household, who lived with one or both of their own parents. This differed from the definition used in previous censuses in which a child had to be never-married, as well as meeting the other criteria specified above.

This change affects a number of the classifications that researchers may use, such as the statistical definition of a family. Prior to 2001, ONS defined a family as either a co-resident couple; a couple and never-married child(ren); a lone parent and never-married child(ren); or a grandparent and never-married child(ren) if the intervening generation was absent. Households refer to co-resident groups sharing common living space, or at least one meal a day, and may include one or more families, or none.

In 2001 the change in the definition of a child meant that the definition of a family also changed, as did descriptions and definitions of households based on the families within them. In 1991 for example, a widowed mother and divorced daughter living together with no-one else would not have been classed as a family, and their household would not have been described as a family household. In 2001 however, the same two people would have been classed as a lone-parent family and their household as a lone-parent household. This change presents difficulties for those undertaking longitudinal analyses who may want to analyse changes in household and family status over census points, or for those who are interested in looking at period changes between different censuses. This article investigates and quantifies the impact of this change.

\section{Family definitions}

In previous research on households, we have derived and used a variable describing the household and family circumstances of LS members at the 1971, 1981 and 1991 Censuses ${ }^{3,4,5,6}$. This takes into account the position of the LS member in the family and household in which they live and relationships with other family and household members. The variable, which we have named 'housefam', includes the following categories: living alone; couple only; couple and children; 
couple and others; couple and children and others; lone parent; lone parent and others; two or more families; not in a family but living with others; child (including adult children) in family; and living in a communal establishment (although in most previous work a collapsed version of this has been used).

Constructing a 2001 version of this using the 2001 definitions of child and family will produce slightly different results from equivalent analyses using the earlier definition. For example, in 2001 a divorced female LS member living with her parents would have been classed as a 'child in family', where previously she would have been classed as 'not in a family but living with others'. If the LS member was the mother of the divorced daughter in the same configuration in 2001 she would be classed as living in a 'couple and child' family/household, but in 1991 or earlier, as living in a 'couple and others' family/household. Fortunately the LS includes information on all those in sample members' households and on intra-family and intra-household relationships, including in 2001 a full relationship grid. It is therefore possible to produce classifications for 2001 using the old (pre 2001) rather than the new child definition. Details of the algorithms, and relevant code (in STATA) for doing this are available on the CeLSIUS web site

\section{The impact of changes in 2001}

The table below shows the distribution of LS members in 2001 by family/household type using alternative definitions of 'housefam' based on either the 2001 or the earlier definition of a child. In each case, if there is any imputed relationship in the household, the family/household type has been set to 'unclassifiable'. Using the wider 2001 definition of a child obviously results in the numbers in categories which include a child being larger than when using the more restrictive 1991 definition. For example using the 2001 definition, 3.5 per cent of LS members were classed as living in a lone parent family, compared with 3.3 per cent using the earlier definition. This difference may seem slight, but differences in the numbers concerned are considerable, given that the LS is a one per cent sample of the population. It is recommended that the impact of these changes be considered when making any comparison between the 2001 Census and previous censuses for statistics relating to households, families and children. 


\section{Table $1 \quad$ Distribution of ONS Longitudinal Study members by family/ household type in 2001 using the 2001 and 1991 (and earlier) definitions of a child}

\begin{tabular}{|c|c|c|c|c|}
\hline & \multicolumn{2}{|c|}{2001 definition } & \multicolumn{2}{|c|}{1991 definition } \\
\hline & Number & $\%$ & Number & $\%$ \\
\hline Solitary & 65,033 & 12.22 & 65,053 & 12.22 \\
\hline Couple only & 120,830 & 22.70 & 120,830 & 22.70 \\
\hline Couple and children & 107,386 & 20.17 & 106,095 & 19.93 \\
\hline Couple and others & 3,721 & 0.70 & 5,098 & 0.96 \\
\hline Couple and child and others & 4,658 & 0.88 & 5,207 & 0.98 \\
\hline Lone parent & 18,495 & 3.47 & 17,725 & 3.33 \\
\hline Lone parent and others & 1,939 & 0.36 & 2,058 & 0.39 \\
\hline 2 or more families & 4,284 & 0.80 & 4,326 & 0.81 \\
\hline Not in a family, with others & 10,850 & 2.04 & 12,270 & 2.31 \\
\hline Child in family (including adult children) & 127,400 & 23.93 & 125,954 & 23.66 \\
\hline Communal establishment & 7,922 & 1.49 & 7,922 & 1.49 \\
\hline Unclassifiable & 59,773 & 11.23 & 59,773 & 11.23 \\
\hline Total & 532,311 & 100 & 532,311 & 100 \\
\hline
\end{tabular}

Notes:

1 The definition of a family includes grandparent(s) living with a grandchild whose parents are not resident in the same household. We did not account for these families when making the new housefam variable. There were only approximately 40 such households who had an ever-married child in the same family, and so a decision was made to leave these families in their original categories.

2 We found that there were approximately 900 never-married children not in the same family as the LS member. We left these as they were, and assumed that they are likely to be never-married children with children of their own, who are therefore part of a separate family.

3 The table above excludes imputed values in the source variables. We have also derived versions of the housefam variables using imputed values. For further information on these and on general derivation of these variables, please see our information pages on derived variables.

\section{References and key publications}

1 CeLSIUS (2009) CeLSIUS training module on households and families. Available at: www.jcelsius.Ishtm.ac.uk/modules/hhfam/hf010000.html

2 Brasset-Grundy A (2003) 'Researching households and families using the ONS Longitudinal Study'. LS User Guide 20. Institute of Education, University of London, London. Available at: www.celsius.Ishtm.ac.uk/documents/userguide20.pdf

3 Grundy E (1987) 'Household change and migration among the elderly in England and Wales'. Espace, Populations, Sociétés 1, 109-123.

4 Grundy E (1999) Household and family change in mid and later life in England and Wales. Published in McRae S (ed.) Changing Britain: Families and Households in the 1990s. Oxford University Press, Oxford.

5 Glaser K and Grundy E (1998) 'Migration and household change in the population aged 65 and over, 1971-1991'. International Journal of Population Geography 4, 323-339. 
6 Grundy E and Jitlal M (2007) 'Socio-demographic variations in moves to institutional care 1991-2001'. Age and Ageing 36(4), 424-430.

7 CeLSIUS (2009) Derived variables: household composition. Available at: www.celsiusdev.Ishtm.ac.uk/private/forclearance/derive/hhcomp.html 